\title{
Factors Influencing Farmers' Decision to Purchase Seed: A Study of Paddy Farmers in Telangana State, India
}

\author{
A. Samarpitha ${ }^{1} *$, N. Vasudev $^{2}$ and K. Suhasini ${ }^{2}$ \\ ${ }^{1}$ Department of Agricultural Economics, Agricultural College, \\ Warangal, PJTSAU, Telangana, India \\ ${ }^{2}$ Department of Agricultural Economics, College of Agriculture, Rajendranagar, \\ PJTSAU, Telangana, India \\ *Corresponding author
}

\section{A B S T R A C T}

\section{Keywords}

Influence, Farmers'

Decision,

Purchase seed,

Telangana

\section{Article Info}

\section{Accepted:}

18 May 2020

Available Online:

10 June 2020
Rice plays a vital role in the national food grain supply and is the main driver of India's food security. Despite having a firm footage on rice cultivation, India is facing a formidable challenge to feed its burgeoning population.Seed is a vital and essential input for attaining sustained growth in agriculture production and productivity. Hence, the present study was taken up to identify the preferences of farmers while purchasing seed from various sources and to estimate the source-wise per unit cost of seed in Nalgonda district of Telangana. The major sources of seed for the sample farmers were found to be Telangana State Seed Development Corporation Ltd. (37.50\%) which supplied followed by State Department of Agriculture (24.17\%) and Primary Agricultural Cooperative Society (20\%). The per unit cost of seed was least (Rs.16.54) for the seed purchased at State Department of Agriculture and highest (Rs. 26.12) for the seed purchased from the private shop keepers. The results indicated large gap between the recommended seed rate and the actual seed rate for the cultivated varieties. Seed quality (69.49) was found to be the most important factor influencing the source of purchase of paddy seed followed by reasonable price (58.71), availability of subsidy for seed (53.54) and timely availability of seed (51.83). Least importance was given to the relationship of the farmer with the seller (36.54). Government should take measures to provide good quality seeds to the farmers at the right time as majority of farmers prefer to buy seeds from a source which provides quality seed. The state department of agriculture as well as co-operative institutions like PACS should be strengthened. Farmers should be educated about the benefits of using recommended seed rate to reduce the gap between the recommended seed rate and the actual seed rate for paddy.

\section{Introduction}

Rice is the most important and extensively grown food crop in the world. Because of its importance in providing national food security and generating employment and incomes for the low-income sectors of society, most Asian governments regard rice as a strategic commodity (Hossain and Narciso, 2004). Rice is the staple food of 
more than 60 per cent of the world population.It plays a vital role in the national food grain supply and is the main driver of India's food security.

Despite having a firm footage on rice cultivation, India is facing a formidable challenge to feed its burgeoning population. Population explosion is exerting more pressure on food security and rice production needs to be multiplied to meet the food demand of ever-growing population in India. At the current population growth rate of 1.5 per cent, the rice requirement of India by the year 2030 would be around 260 million tonnes (Reddy and Sen, 2004). The opening of the agricultural sector for exports has aggravated the problem and has increased the pressure on the Indian farmers to produce more.

Seed being the fundamental input in crop production, its high quality forms the basis of high productivity. Although seed accounts for a minor portion of the total costs in a majority of crops, on this vital input depends the returns one obtains from land using other costly inputs like farm machinery, irrigation, chemical fertilizers, pesticides, labour, etc. Much of the efforts and investment would be unfructuous if one does not use quality seeds (Verma and Sidhu, 2009).

Seed is a crucial, vital, basic and essential input for attaining sustained growth in agriculture production and productivity. A sustained increase in agriculture production and productivity has depended on the development of new improved variety, timely and adequate supply of quality seed to the farmers. It is estimated that the direct contribution of quality seed alone to the total production is about 15-20 per cent depending upon the crop and it can be further raised up to 40 per cent with effective management of other inputs.
The general farm produce retained for seed cannot be substituted for quality seed as it generally lacks genetic vigour and has poor germination (Singh et al., 1990). Quality of seeds is intrinsically linked to crop yield and production, implying better the quality of seeds, better the yield (Singh and Kumar, 2014).

Given the importance of seed, the present study has been undertaken with the following objectives that include to identify various sources of paddy seed purchased by the farmers and find out the source-wise per unit cost of seed. Then, to study the variety-wise preference and seed rate adopted by the sample farmers. And also to identify the factors influencing farmers' selection of agencies for purchase of paddy seeds

\section{Description of the study area}

Telangana state is situated on the Deccan Plateau covering 114,840 square kilometres and bordered bythe states of Maharashtra to the north, Chattisgarh to the north east, Karnataka to the west, Rayalaseemaregion to the south west and coastal Andhra region to the south east. The region is drained by two major rivers, with about $79 \%$ of the Godavari river catchment area and about $69 \%$ of the Krishna river catchment area and several minor rivers such as the Bhima, the Manjira and the Musi. The region is semi-arid and has a predominantly hot and dry climate.

The economy of Telangana region is mainly driven by agriculture with rice as the major food crop and staple food of the state. Other important crops include maize, tobacco, mango, cotton and sugarcane. There are many irrigation projects in the region including Godavari River Basin Irrigation Projects and Nagarjuna SagarDam, the world's highest masonry dam. Nalgonda is one of the districts in the Telangana state. Nalgonda is located in 
Southern Telangana zone which receives 700$900 \mathrm{~mm}$ rainfall. Agriculture is one of the main occupations in Nalgonda. It is supported by a well- planned irrigation system which includes 26 lift irrigation and 1,16,007 irrigation wells. Nagarjuna Sagar, the major irrigation project provides irrigation facilities to the extent of 1.24lakh hectares in the district. Major crops grown in the district include rice, pulses, mousambi or lime, millets and oilseeds.

\section{Materials and Methods}

\section{Database and methodology}

Multistage stratified random sampling technique was adopted for selection of the sample with district as the first stage unit, mandals/tehsils as the second stage units, villages as the third stage units and farm holdings as the final and ultimate stage units. In the first stage, Nalgonda district with highest production of rice was selected.

Considering district as a unit, two prominent rice growing mandals namely Miryalguda and Nidamanur were selected. From each mandal three villages were selected randomly. Thus a total of six villages were selected for the study. In each selected village, rice cultivators were stratified into five groups based on the size of operational holding viz., marginal $(<1$ ha), small (1-1.99 ha), semi-medium (2-3.99 ha), medium (4-9.99 ha) and large (>10 ha) following the classification given by Agriculture Land use census, Ministry of Agriculture. From each farm-size group four farmers were selected randomly making a total of twenty farmers from each selected village. Thus the sample consisted of 1 district, two mandals, six villages (three villages from each mandal) and 120rice farmers (twenty from each village). The primarydata of the selected rice farmers were obtained through personal interview method with the help of pre-tested comprehensive interview schedule.

The information was collected from the sample farmers regarding the size of their operational holdings, variety-wise farmer's preference, sources of seed, seed rate, etc.

\section{Tools of analysis}

Descriptive/tabular analysis involving the computation of means and percentages were employed to present the data. Garrett's Ranking Technique was employed to find out the most important factors influencing the sample farmers in selecting source for purchasing paddy seed. It is calculated as percentage score and the scale value is obtained by employing Scale Conversion Table given by Henry Garrett.

The Percentage Score is calculated as

$100 *(\mathrm{Rij}-0.5) / \mathrm{Nj}$

Where, $R_{i j}$ is Rank given for $i^{\text {th }}$ item $j^{\text {th }}$ individual

$\mathrm{N}_{\mathrm{j}}$ is Number of items ranked by $\mathrm{j}^{\text {th }}$ individual

The percentage score for each rank from 1 to 10 are calculated. The percentage scores thus obtained for all the ten ranks are converted into scale values using Scale Conversion Table given by Henry Garrett. The scale values for first rank to tenth rank are 82,70 , $63,58,52,48,42,36,29$ and 18 respectively. The score value is calculated for each factor by multiplying the number of respondents with respective scale values. The total scores are found by adding the score values of each rank for every factor. The mean score is then calculated to know the order of preference given by the respondents for the factors. Based on the mean score, the overall ranks are assigned for each parameter. 


\section{Results and Discussion}

\section{Source of purchasing paddy seed}

The various sources from which sample farmers purchased paddy seed were Telangana State Seed Development Corporation Ltd. (TPSSDC), State Department of Agriculture, Primary Agricultural Cooperative Society (PACS), market yard, private dealers and self-retained seed. The different sources from which the sample farmers purchased the seed have been depicted in Fig. 1.The study found out that majority of the sample farmers $(37.50 \%)$ purchased seed from Telangana State Seed Development Corporation Ltd., Nidamanuru. It was because TSSDC provides quality seeds tested at central quality control lab which is a recognized and approved seed testing lab by Government of India. Another reason could be due to proximity of sample farmers to TSSDC.

The next important source of paddy seed was State Department of Agriculture (24.17\%) which provided seed on subsidy basis. If the cost of $30 \mathrm{~kg}$ seed was Rs.750-900 in the market, the subsidised seed was made available for Rs. 560-600.

The third most important source of paddy seed was Primary Agricultural Cooperative Society (PACS) located at Miryalaguda (20\%) which provided subsidised seed on credit basis to those farmers who were members of the Cooperative Society. Other sources included private seed dealers $(14.17 \%)$ which was due to good contacts between sample farmers and private seed dealers. Market yard was another source from where $2.5 \%$ of the sample farmers purchased the seed. Apart from these sources, $1.67 \%$ of the sample farmers used self-retained seed from the previous season. A very low percentage of self-retained seed indicated low preference of farmers for the same. This may also be because paddy was harvested using combine harvesters in the study area and the percentage of broken grains/ seeds was higher than in manual harvesting.

The farm category-wise analysis indicated that in all categories, majority of the farmers preferred to procure paddy seed from Telangana State Seed Development Corporation Ltd. (TSSDC).

\section{Source-wise per unit cost of seed}

The per unit cost of seed purchased by the sample farmers from various sources is given in Fig 2.

The results indicated that the per unit cost of seed was least (Rs.16.54) for the seed purchased at State Department of Agriculture and highest (Rs. 26.12) for the seed purchased from the private shop keepers. There was a difference of approximately Rs.10 per unit between these two sources of seed. Though the per unit cost of seed at TSSDC was higher (Rs. 21.68) compared to the State Department of Agriculture (Rs.16.54), majority of the farmers preferred TSSDC to purchase the seed due to availability of quality seed.

\section{Variety-wise preference and seed rate}

All the farmers in the study area cultivated BPT-5204 (Samba Mahsuri) during kharif andMTU-1010 (Cotton dora sannalu) during rabi season. The seed rate $\left(\mathrm{kg} \mathrm{ha}^{-1}\right)$ adopted by the sample farmers is given in Table 2 . The results indicated large gap between the recommended seed rate and the actual seed rate for both the varieties. The recommended seed rate for BPT-5204 (kharif) is $50 \mathrm{~kg} \mathrm{ha}^{-1}$ whereas the seed rate adopted by sample farmers was $71.04 \mathrm{~kg} \mathrm{ha}^{-1}$. The recommended seed rate for MTU-1010(rabi) is $62.5 \mathrm{~kg} \mathrm{ha}^{-1}$ to $75 \mathrm{~kg} \mathrm{ha}^{-1}$ and the average seed rate adopted by the sample farmers was $74.17 \mathrm{~kg}$ $\mathrm{ha}^{-1}$. 
The quantity of seed used per hectare of rice was more in rabi than in kharif because sample farmers reported that50-60 kg ha ${ }^{-1}$ of seed was insufficient for obtaining a good yield. During kharif, highest seed rate $(73.44$ $\mathrm{kg} \mathrm{ha}{ }^{-1}$ ) was adopted by small farmers whereas lowest seed rate was adopted by medium farmers $\left(68.23 \mathrm{~kg} \mathrm{ha}^{-1}\right)$. However, in rabi there was not much variation in the seed rate adopted by the sample farmers.

Factors influencing farmers' selection of agencies for purchase of paddy seeds

Garrett ranking technique was used to analyse the factors influencing the source of purchase of seed by the respondents.

The results from table 4 indicate the various factors which influence the sample farmers in selecting the source of purchasing seed. The study revealed that seed quality (69.49) was the most important factor influencing the purchase of paddy seed followed by reasonable price (58.71), availability of subsidy for seed (53.54) and timely availability of seed (51.83). Least importance was given to relationship with the seller (36.54).

Table.1 Category-wise purchase of seed at various sources

\begin{tabular}{|l|c|c|c|c|c|c|}
\hline Farm holding & $\begin{array}{c}\text { AO } \\
\text { Office }\end{array}$ & TSSDC & $\begin{array}{c}\text { Market } \\
\text { yard }\end{array}$ & $\begin{array}{c}\text { PACS, } \\
\text { Miryalguda }\end{array}$ & $\begin{array}{c}\text { Private } \\
\text { shop }\end{array}$ & Total \\
\hline Marginal & 6 & 8 & - & 5 & 5 & 24 \\
& $(25.00)$ & $(33.33)$ & & $(20.83)$ & $(20.83)$ & $(100.00)$ \\
\hline Small & 7 & 9 & - & 3 & 5 & 24 \\
& $(29.17)$ & $(37.50)$ & & $(12.50)$ & $(20.83)$ & $(100.00)$ \\
\hline Semi-medium & 5 & 9 & - & 6 & 4 & 24 \\
& $(20.83)$ & $(37.50)$ & & $(25.00)$ & $(16.67)$ & $(100.00)$ \\
\hline Medium & 6 & 9 & 2 & 4 & 3 & 24 \\
& $(25.00)$ & $(37.50)$ & $(8.33)$ & $(16.67)$ & $(12.50)$ & $(100.00)$ \\
\hline Large & 5 & 10 & 1 & 6 & 2 & 24 \\
& $(20.83)$ & $(41.67)$ & $(4.17)$ & $(25.00)$ & $(8.33)$ & $(100.00)$ \\
\hline
\end{tabular}

Note: Figures within the parentheses indicate percentages of the respective row totals

Table.2 Seed rate $\left(\mathrm{kg} \mathrm{ha}^{-1}\right)$ adopted by the sample farmers

\begin{tabular}{|l|c|c|}
\hline Category & Kharif (BPT-5204) & Rabi (MTU-1010) \\
\hline Marginal & 71.88 & 73.96 \\
\hline Small & 73.44 & 73.96 \\
\hline Semi-medium & 71.88 & 73.96 \\
\hline Medium & 68.23 & 74.48 \\
\hline Large & 69.79 & 74.48 \\
\hline Average seed rate & 71.04 & 74.17 \\
\hline
\end{tabular}


Table.3 Percentage Positions and their corresponding Garett's Table values

\begin{tabular}{|l|l|c|c|}
\hline Rank & \multicolumn{2}{|c|}{ Percentage position } & Garrett table \\
\hline $\mathbf{1}$ & $100 *(1-0.5) / 10$ & 5 & 82 \\
\hline $\mathbf{2}$ & $100 *(2-0.5) / 10$ & 15 & 70 \\
\hline $\mathbf{3}$ & $100 *(3-0.5) / 10$ & 25 & 63 \\
\hline $\mathbf{4}$ & $100 *(4-0.5) / 10$ & 35 & 58 \\
\hline $\mathbf{5}$ & $100 *(5-0.5) / 10$ & 45 & 52 \\
\hline $\mathbf{6}$ & $100 *(6-0.5) / 10$ & 55 & 48 \\
\hline $\mathbf{7}$ & $100 *(7-0.5) / 10$ & 65 & 42 \\
\hline $\mathbf{8}$ & $100 *(8-0.5) / 10$ & 75 & 36 \\
\hline $\mathbf{9}$ & $100 *(9-0.5) / 10$ & 85 & 29 \\
\hline $\mathbf{1 0}$ & $100 *(10-0.5) / 10$ & 95 & 18 \\
\hline
\end{tabular}

Table.4 Factors influencing the sample farmers in selecting the source of purchasing seed

\begin{tabular}{|l|c|c|c|c|c|c|c|c|c|c|c|c|c|}
\hline Rank & I & II & III & IV & V & VI & VII & VIII & IX & X & $\begin{array}{l}\text { Total } \\
\text { Score }\end{array}$ & $\begin{array}{l}\text { Mean } \\
\text { score }\end{array}$ & Rank \\
\hline Scale & $\mathbf{8 2}$ & $\mathbf{7 0}$ & $\mathbf{6 3}$ & $\mathbf{5 8}$ & $\mathbf{5 2}$ & $\mathbf{4 8}$ & $\mathbf{4 2}$ & $\mathbf{3 6}$ & $\mathbf{2 9}$ & $\mathbf{1 8}$ & & & \\
\hline Factors & & & & & & & & & & & & & \\
\hline Reasonable Price & 25 & 18 & 22 & 13 & 9 & 7 & 8 & 3 & 7 & 8 & 7045 & 58.71 & 2 \\
\hline Seed quality & 51 & 25 & 13 & 10 & 9 & 6 & 6 & 0 & 0 & 0 & 8339 & 69.49 & 1 \\
\hline $\begin{array}{l}\text { Availability of } \\
\text { credit }\end{array}$ & 14 & 12 & 11 & 25 & 10 & 9 & 9 & 12 & 18 & 0 & 5882 & 49.02 & 6 \\
\hline $\begin{array}{l}\text { Timely availability } \\
\text { of seed }\end{array}$ & 8 & 6 & 10 & 19 & 24 & 22 & 14 & 7 & 8 & 2 & 6220 & 51.83 & 4 \\
\hline $\begin{array}{l}\text { Subsidy for seed } \\
\text { Proximity to the }\end{array}$ & 14 & 11 & 11 & 15 & 20 & 15 & 11 & 11 & 10 & 2 & 6425 & 53.54 & 3 \\
\hline Source & 6 & 12 & 6 & 13 & 17 & 3 & 22 & 19 & 20 & 5009 & 41.74 & 8 \\
\hline $\begin{array}{l}\text { Availability of } \\
\text { desired variety }\end{array}$ & 2 & 15 & 18 & 16 & 12 & 12 & 15 & 9 & 12 & 9 & 5940 & 49.50 & 5 \\
\hline $\begin{array}{l}\text { Relationship with } \\
\text { the seller }\end{array}$ & 2 & 6 & 0 & 7 & 6 & 15 & 18 & 19 & 7 & 40 & 4385 & 36.54 & 10 \\
\hline $\begin{array}{l}\text { Reputation of the } \\
\text { source in sale of } \\
\text { seed }\end{array}$ & 1 & 11 & 12 & 4 & 9 & 14 & 17 & 17 & 15 & 20 & 5101 & 42.51 & 7 \\
\hline \begin{tabular}{l} 
Past experience \\
\hline
\end{tabular} & 1 & 10 & 11 & 5 & 8 & 3 & 19 & 20 & 24 & 19 & 4881 & 40.68 & 9 \\
\hline
\end{tabular}


Fig.1 Sources of paddy seed purchased by sample farmers

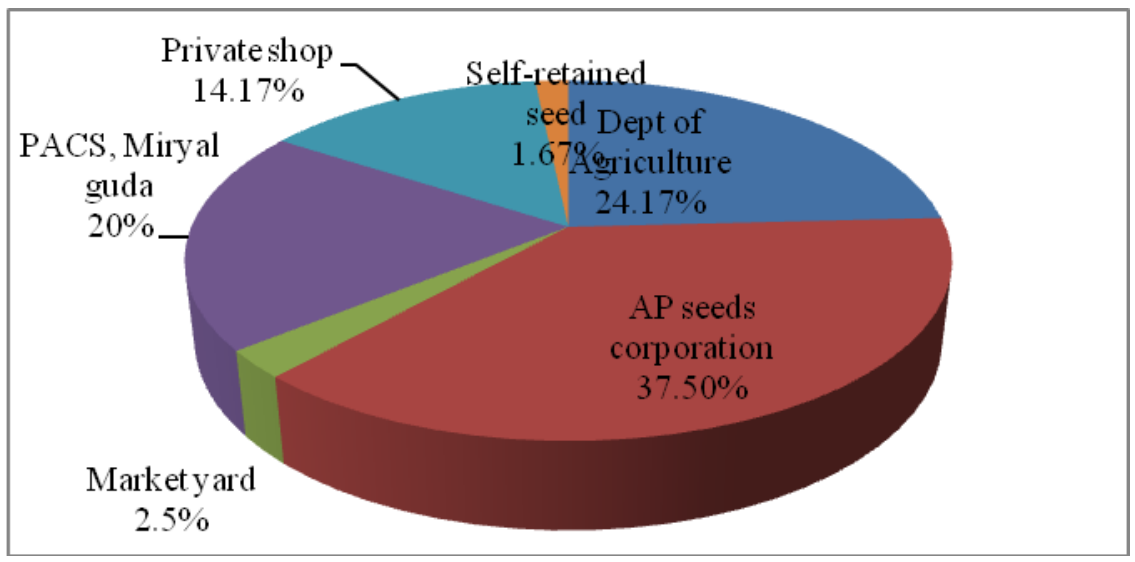

Fig.2 Per unit cost of seed at different sources (In Rupees)

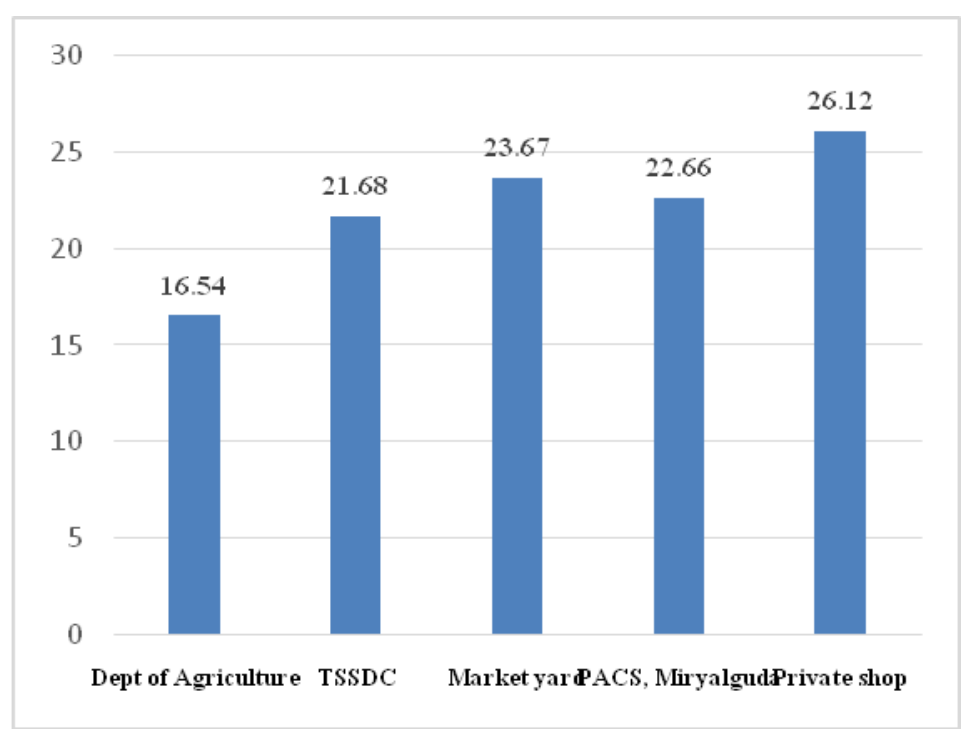

Conclusion of the study is as follows:

The present study sought to identify the preferred sources of purchasing paddy seed, variety-wise preference, seed rate adopted by sample farmers, source-wise per unit cost of seed and the factors influencing farmers' selection of agencies for purchase of paddy seeds.

The major sources of seed for the sample farmers were Telangana State Seed Development Corporation Ltd.(37.50\%)which supplied quality seed, State Department of
Agriculture (24.17\%) and Primary Agricultural Cooperative Society (20\%).The farm category-wise analysis also indicated that in all categories of marginal, small, semimedium, medium and large farmers, majority of the farmers preferred to procure paddy seed from Telangana State Seed Development Corporation Ltd.

The per unit cost of seed was least (Rs.16.54) for the seed purchased at State Department of Agriculture and highest (Rs. 26.12) for the seed purchased from the private shop keepers. The sample farmers cultivated BPT-5204 
(Samba Mahsuri) during kharif and MTU1010 (Cotton dora sannalu) during rabi in the study area. The results indicated large gap between the recommended seed rate and the actual seed rate for both the varieties. The study revealed that seed quality (69.49) was the most important factor influencing the source of purchase of paddy seed followed by reasonable price (58.71), availability of subsidy for seed (53.54) and timely availability of seed (51.83). Least importance was given to relationship with the seller (36.54).

Quality of seeds is related to crop yield and production. Government should take measures to provide good quality seeds to the farmers at the right time as majority of farmers prefer to buy seeds from a source which provides quality seed. The state department of agriculture as well as cooperative institutions like PACS should be strengthened. Farmers should be educated to follow the recommended seed rate and its benefits to reduce the gap between the recommended seed rate and the actual seed rate for paddy.

\section{References}

Hossain, M and Narciso, J. 2004. Global rice economy: Long-term perspectives. FAO

Conference on Rice in Global Markets and Sustainable Production Systems, Rome, Italy, 12-13 February, 2004.

Reddy, A. R and Sen, C. 2004. Technical efficiency in rice production and its relationship with

farm-specific socio-economic characteristics. Indian Journal of Agricultural Economics. 59 (2): 259-267.

Singh, G., Asokan, S. R. and Asopa, V.N. 1990. Seed Industry in India - A Management

Perspective. Oxford \& IBH Publishing Co. (Pvt.) Ltd., New Delhi.

Singh, S.P. and Kumar, N. 2014. Rice seeds availability in India and Bangladesh farmers' perspective. Briefing Paper 4/2014. Centre for International Trade, Economics \& Environment(CUTS CITEE).

Verma and Sidhu. 2009. Sources, Replacement and Management of Paddy Seed by Farmers in

Punjab. Agricultural Economics Research Review. 22 (3): 323-328.

\section{How to cite this article:}

Samarpitha, A., N. Vasudev and Suhasini, K. 2020. Factors Influencing Farmers' Decision to Purchase Seed: A Study of Paddy Farmers in Telangana State, India. Int.J.Curr.Microbiol.App.Sci. 9(06): 2320-2327. doi: https://doi.org/10.20546/ijcmas.2020.906.284 